\title{
WORK PACKAGE: \\ Real-time Data Processing in Adaptive Sensor Interfaces
}

http://saturn.acad.bg/bis/signal/signal2.htm

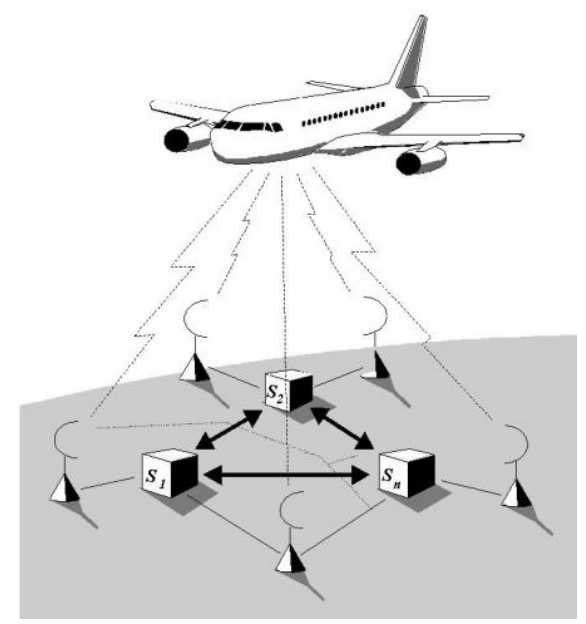

\section{Objectives:}

- Exchange of knowledge and expertise

- Solution of challenging problems

- Enhancement of research capabilities

- $\quad$ Education and training

\section{Methodology:}

- Research co-operation

- Visits exchange

- Conference organization 


\section{Actions:}

- Study of advanced sensor's interfaces

- Design of new methods and algorithms

- Development of software libraries

- Results dissemination

\section{Partners:}

- Leuven Katholieke Universiteit, Belgium;

- University of Bristol, UK;

- University of New Orleans, US;

- ONERA, France

\section{Deliverables:}

- Modern education

- Information center and Web site

- International conference

- Advanced algorithms and software

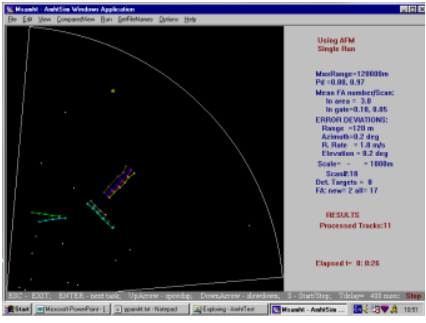

Multiple Target Tracking

- Data Association

- Boot Satrap Estimation

- Stochastic Sampling

- $\quad$ Tracking in Clutter

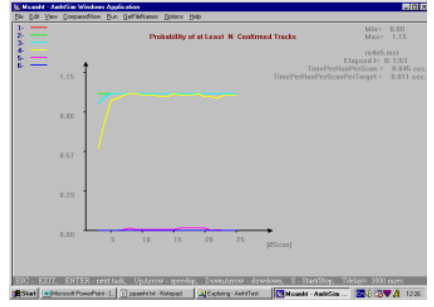

Situation Assessment

- Paradoxical Reasoning

- Fuzzy Modeling

- Tendency Estimation

- Active Sensing 